\title{
A novel speed control technique for single-phase induction motor
}

\author{
A.S.ZEIN EL-DIN and A.E.EL-SABBE \\ Department of Electrical Engineering, Faculty of Engineering, Shebin El-Kom, Egypt,
}

Tel. (048)221549, Fax.: (048) 235695, e-mail: IN\%"et001@shebin.eun.eg".

\begin{abstract}
In this paper, a novel speed control of a single phase induction motor is proposed using a modified inverter. Three MOSFETs are used for controlling the flux linkage of a single phase transformer, its secondary winding is connected in serjes with the motor. On-line Bang-Bang speed control of motor scheme is implemented using a microprocessor to derive the inverter. A mathematical model for the single-phase induction motor is presented, which is used to build up a simulation program for a certain desired speed. Experimental results have been carried out to investigate the motor performance with the controller. Good agreement has been obtained between simulation and experimental results.
\end{abstract}

\section{Keywords}

Microprocessor, Flux linkage, MOSFET, Bang-Bang control, and single-phase induction motor.

\section{Introduction}

The high-performance inverter technology realizes many new application fields. The $\mathrm{dc} / \mathrm{ac}$ static inverters permit feeding the complex systems, providing a low rate of harmonic distortion, high efficiency, rapid dynamic response and competitive cost. The great inconvenience found in these inverters lies in the great power dissipation during turn on and turn off of the semiconductors, and in turn limiting the inverter frequency. This problem prevents the reduction of weight, volume and cost for the system as a whole [1-4].

Pulse-Width Modulation (PWM) schemes for dc-ac power conversion have received much attention, in the last two decades. Many PWM schemes have been developed and implemented successfully for different applications. Variable-speed induction motor drives have found widespread use of pulse-width modulation inverters. In many applications, a further cost reduction for the drive is an important aspect and, thus, a reduction of the number of power semiconductors in the converter should be a main consideration [5-6]. In recent years, numerous pulse width modulation pattern generation techniques have been developed for improving the performance [2-7].

Manuscript Received From Dr. A.S. Zein El-Din and A.E. El-Sabbe. on: 11/10/1998. Accepted on : 22/10/1998. Engineering Research Bulletin Vol.22, No.1, 1999.

Minufiya University, Faculty of Engineering, Shebin CI-Kom, EGYPT, iss. 1110-1180. 
When an induction motor fed by a voltage source inverter, the applied stator voltage wave forms contain harmonics generated by the PWM technique and the system stability will be affected by these harmonics especially at low frequencies.

This paper is presents a speed control of a single-phase induction motor fed by the proposed inverter. Such a system can be used in the industrial applications, which required smooth variation of speed with high response, also in controlling speed of car vechals, and robot motion. The proposed systems requires only three MOSTETs and gives an output ac voltage can be controlled in a wide range to give smooth variation of motor speed .

\section{System operation and analysis}

In this section, the proposed system shown in Fig. 1 , is described and analyzed. MOSFETs 1 and 2 transfer the input voltage to the output load (motor) through step-up transformer, which having a rating more than the load rating,. MOSFET 3 connected in parallel across the load (transformer primary) to prevent any opposite voltage in the output, either in positive or negative half cycle, also to reduce the output spikes and improving the output voltage $V_{L}$. The MOSFETs switching are controlled by using PWM technique. The driver circuits (shown in Fig.2) are feeding from a microprocessor to arrange the switching process, according to the reference control voltage (Ref) and feed back signal from the motor speed $(\mathrm{N})$ through a tacho-generator. MOSFET 3 is switched on if and only if either MOSFET 1 or MOSFET 2 is turned off to prevent the opposite voltage due to the load inductance (transformer and motor).

A square wave signal with $50 \mathrm{~Hz}$ to the microprocessor is used to achieve synchronization between the MOSFETs pulses and the applied voltage to the motor. This circuit is used if an ac supply exists to recognize the frequency of the waveform of the output voltage, but, in case of the absence of the ac supply, a timer is used to achieve a fixed load voltage frequency. Comparing between reference speed (Ref.) and the motor speed (tacho-generator feed back signal ) through summing circuit used to give the error signal e, A/D circuit transfers the error signal $e$ to the microprocessor for arranging the MOSFETs switching. Applying bang - bang control action [6] as follows; if $e>$ zero hence turn on MOSFETs 1 or 2 , depending on positive or negative load voltage, otherwise if $\mathrm{e} \leq$ zero hence turn off MOSFETS 1 or 2 .

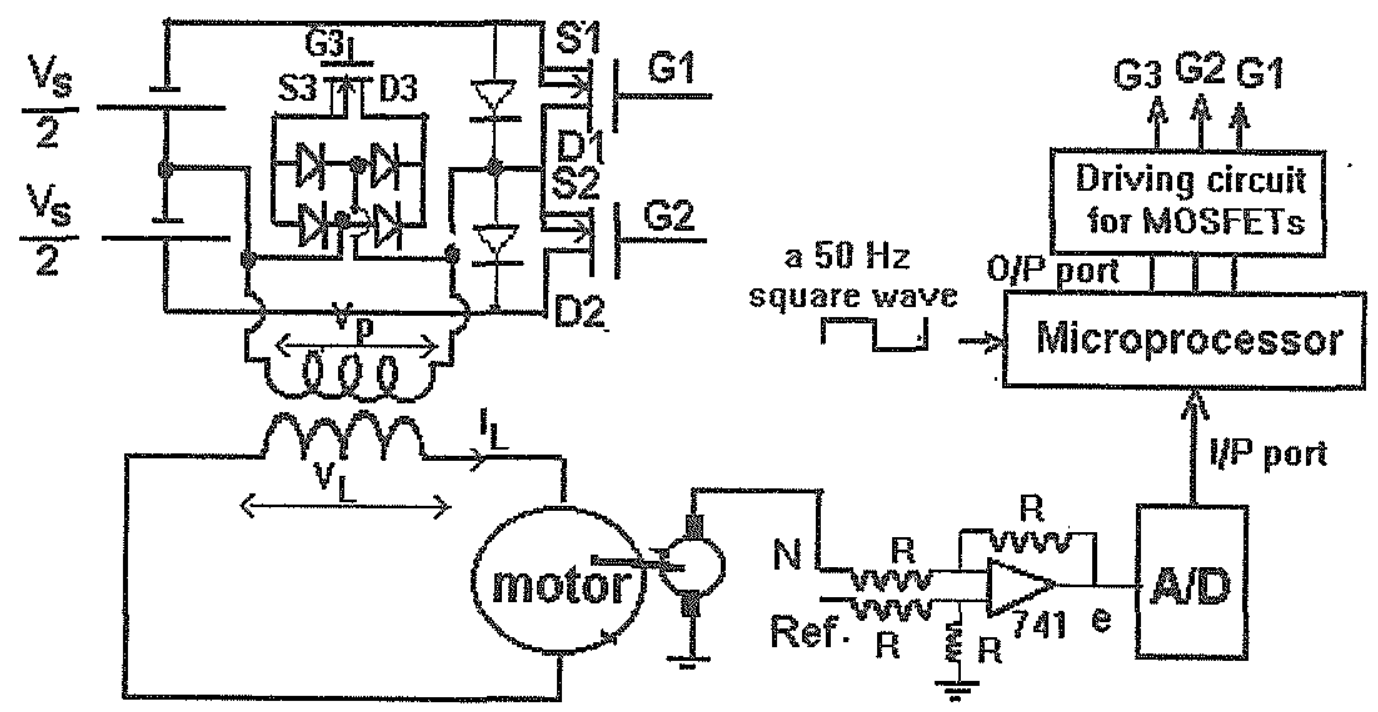

Fig. 1 A schematic diagram of the proposed system 


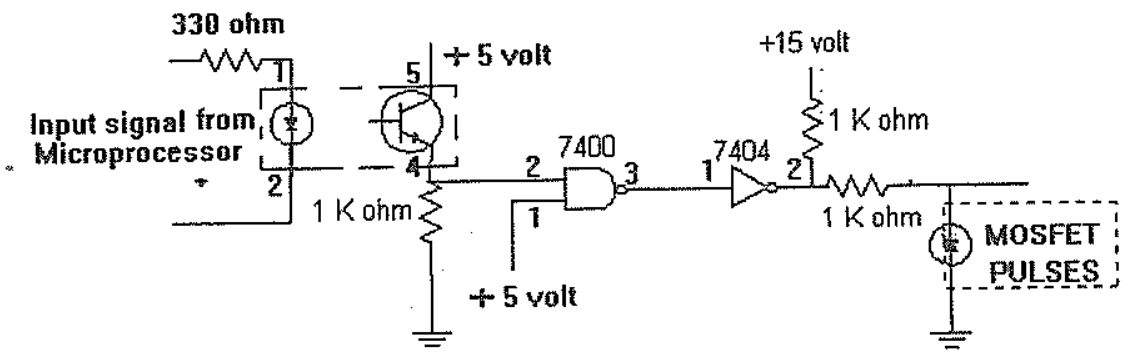

Fig. 2 Driver circuit for MOSFET

\section{Motor mathematical model}

For running capacitor single phase induction motor, the motor equations in $\mathrm{d}-\mathrm{q}$ axis (Fig. 3) can be written as follows:[9]

$V_{m}=\left(R_{m}+L_{m} \rho\right) i_{m}+M \rho i_{\alpha}$

$V_{m}-V_{c}=\left(R_{a}+L_{a} \rho\right) i_{a}+A_{s} M \rho i_{\beta}$

$0=M \rho i_{m}-A_{S} M \frac{d \theta}{d t} i_{a}+\left(R_{r}+L_{\Gamma} \rho\right) i_{\alpha}-L_{r} \frac{d \theta}{d t} i_{\beta}$

$0=M \frac{d \theta}{d t} i_{m}+A_{S} M \rho i_{a}+L_{r} \frac{d \theta}{d t} i_{\alpha}+\left(R_{r}+L_{r} \rho\right) i_{\beta}$

where $v_{c}=\frac{1}{c} \int i_{a} d t$

The instantaneous electromagnetic torque may be expressed in terms of substitute variables as:

$T_{e}=P M\left(i_{\beta} i_{m}-I_{\gamma \gamma} i_{a} A_{s}\right)$

The equation of motion can be written as follows:

$J \frac{d \omega_{X}}{d t}=T_{e}-T_{L}-K \omega_{r}$

The present model is valid for both steady-state and transient conditions.

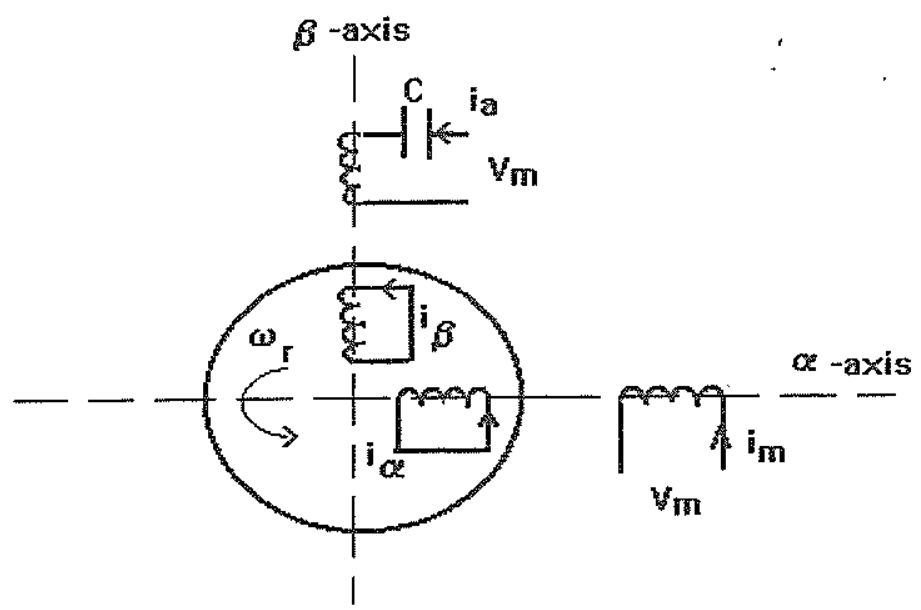

Fig.3 Representation of single-phase induction motor 


\section{System performance and results}

In order to evaluate the performance of the proposed system, dc source used with suitable value and must be free of ripples and accepted recovery power such as car batteries, where the dc voltage supplied inverter has great influence of its operation. An experimental circuit has been built according to Fig .1 and tested at the laboratory to evaluate the motor performance under different conditions of operation .

For single phase running capacitor induction motor with parameters shown in Appendix (a), two batteries of 12 volt each (Vs/2) are used as a dc source, power devices are MOSFETs, type IRFP740. A pulse width modulation control is achieved using microprocessor 8085, and Bang-Bang control technique Algorithm is used, an Assembly program is written and stored in an EPROM interfaced with the microprocessor to achieve that technique. Figures 4-7, show the experimental and simulation waveforms of the motor speed, terminals voltage and current during startup period and steady state interval at reference speed $=1040$ r.p.m., the spikes in the experimental waveform may be due to the motor and transformer inductance. The motor performance under steady state condition is shown in Figs.8-9. When a change in the reference speed is occurred, the motor response is shown in Figs. 10,11. It is noticed that the motor response follows the reference speed. This means that the proposed controller is aicurate and smooth on the period of change. Figures 12,13 show the motor response when the load torque is changed by $60 \%$ of fall load torque.

\section{5. conclusion}

This paper describes a novel method of speed control of an ac motor (single-phase running capacitor inducion motor) by adjusting the flux linkage between two magnetic coils using a modified inverter and Bang-Bang control. This strategy influences the effective equivalent inductance of two coils connected in series with the motor, consequently control the motor applied voltage. Simulation and experimental study have shown that, by this method of control the speed of the motor can be changed smoothly from zero value to the rated speed with high response.

\section{References}

1- S.Y.R . Hui, Opperman and S. Sathiakumer ,"Microprocessor-Based random PWM schemes for dc-ac power conversion", IEEE Transaction on power electronic, vol. 12, No. 2, March 1997, pp 253-260.

2-Michihiko and Koosuke, "inductor commutation soft switched PWM inverter driven by frequency modulated PWM signal ", IEEE Transaction on power electronic, vol. 13, No: 1, January 1997, pp 67-74 .

3-Falconds Jose Mendes De Seixas and Denizar Cruz Martins, "The ZVS-PWM commutation cell applied to dc-ac converter ", IEEE Transaction on power electronic, vol. 12, No. 4, July 1997, pp 726-733.

4-Frede Blaabjerg, Sigurdur Freysson, Hans- Hernik Hansen and S.Hansen, "A new optimized space vector modulation strategy for a component-minimized voltage source inverter", IEEE Transaction on power electronic,vol.12,No.4, July 1997,pp704-714

5-Awad El-sabbe and Ashraf Zein El-Din, "Speed control of a single phase ac motor by using ac voltage regulator ", accepted in MEPCON' 98 , El-Mansoura-Egypt , 14-16 December 1998 
6-S.A.Mahmoud, A. S.Zein El-Din and A .E. El-Sabbe, "PLC-Based control of UPS ", Accepted in PEMC' 98, Techequ republic, 8-10 September 1998.

7-J.Marcos Alonson, Cecilio Blanco and Manuel Rico, "Analysis, Design, and optimization of the LCC resonant inverter as a high intensity discharge lamp ballast", IEEE Transaction on power electronic, vol. 13, No. 3, May 1998, pp 573-585.

8-David Leggate and Russel J. Kerkman", Pulse-Based dead-time compensator for PWM voltage inverters", IEEE Transaction on power electronic, vol.44, No.2, April 1997, pp.191-199.

[9] A. S.Zein El-Din and A .E. El-Sabbe and S.A.Mahmoud,"A novel ac voltage regulator", IECON98, 24 th Annual conference of the IEEE Industrial Electronics Society, Aachen-Germany, Volume 2/4, August 31-September 4, 1998, pp.607-611

[10] S.S.Shokralla and A.M.Kinawy," Perturbation analysis of a single-phase capacitor induction motor in time and frequency domains", Eng. Research bull. Faculty of Eng., Menoufia university, Vol. 16, No.2, pp.179-201, 1993.

\section{Appendix (a)}

The single phase running capacitor induction motor has :

A 110 volt. rated voltage., 0.5 amp rated current and 2770 r.p.m. rated speed, $\mathrm{Ls}=\mathrm{Lr}=$ $0.25 \mathrm{H}, \mathrm{Rr}=50 \Omega ., \mathrm{R}_{\mathrm{s}}=69.76 \Omega, \mathrm{M}=0.6 \mathrm{H}, \mathrm{C}=3 \mu \mathrm{F}$, and $\mathrm{As}=1$

Transformer rated current: 3 amp

\section{SymboIs}

$A_{s}:$ Auxiliary to main winding turns ratio.

$i_{a}, i_{m}$ : Auxiliary and main winding current.

$\mathrm{i}_{\alpha}, \mathrm{i}_{\beta}$ : rotor current.in $\alpha$ and $\beta$ axis.

$\mathrm{J}$ : Moment of inertia in $\mathrm{Kg} \cdot \mathrm{m}^{2}$

$\mathrm{L}_{\mathrm{a}}, \mathrm{L}_{\mathrm{m}}, \mathrm{L}_{\mathrm{r}}$ : Auxiliary, main and rotor winding self inductance.

M: Main to rotor mutual inductance.

$\mathrm{K}$ : Friction constant.

P: number of pair poles.

$\rho: \mathrm{d} / \mathrm{dt}$

$R_{a}, R_{m}, R_{r}$ : Auxiliary, main and rotor winding resistance,

Te: Electromagnetic developed torque.

$\mathrm{T}_{I}$ : Load torque.

$\mathrm{V}$, : Supply voltage

Vc: capacitor terminal voltage

$\mathrm{V}_{\mathrm{m}}$ :Amplitude of a.c. Input voltage

$\Theta:$ Electrical angle between stator and rotor.

$\omega_{\mathrm{r}}:$ Motor speed in $\mathrm{rad} / \mathrm{sec}=\mathrm{d} \Theta / \mathrm{dt}$ 


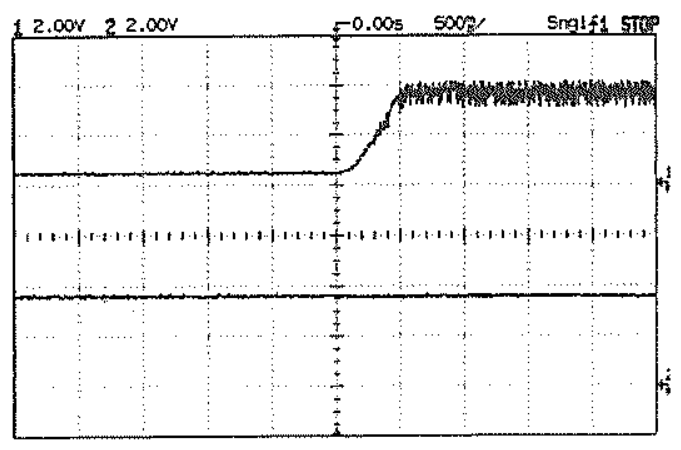

Figure 4 Experimental results of

Ch.1 Motor speed

Ch.2 Reference speed

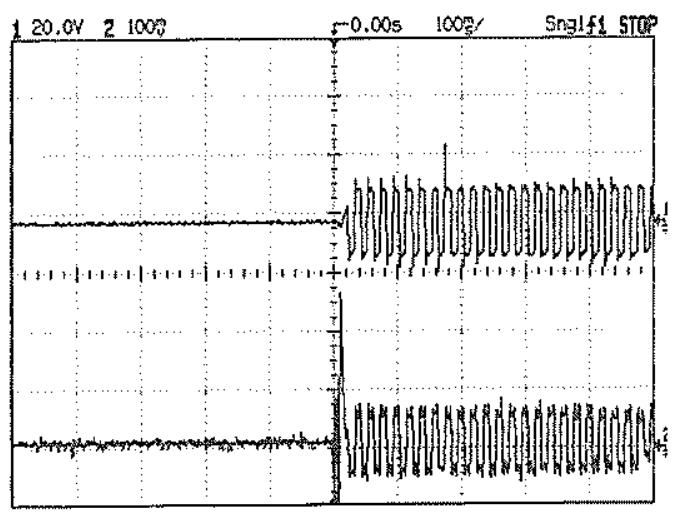

Figure 6 Start up of motor terminal voltage and current (Experimental results)

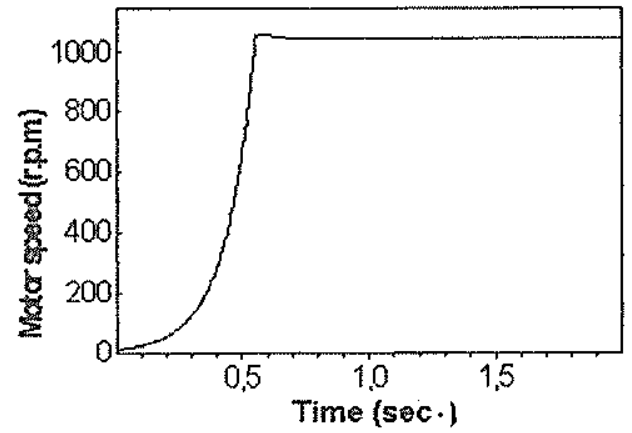

Figure 5 Motor speed (Simulation result)
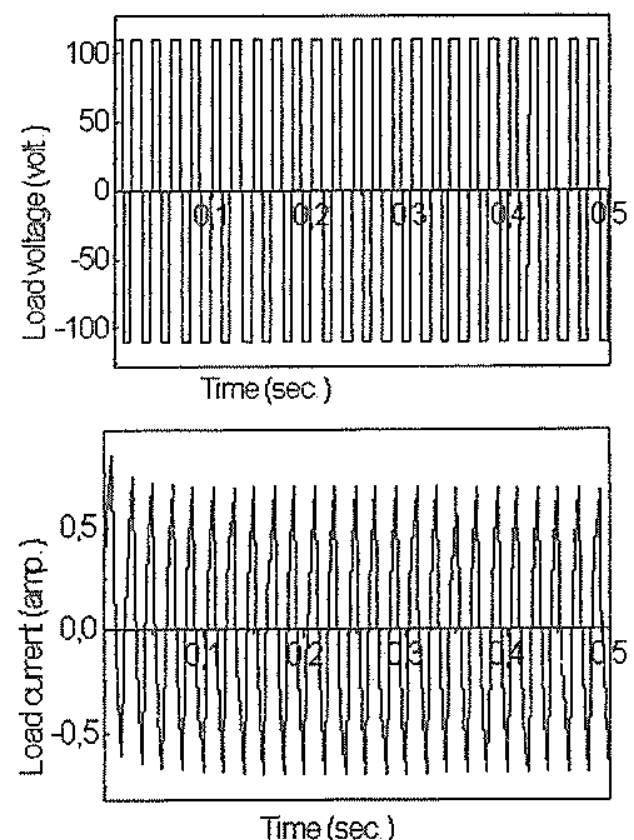

Figure 7 Start up of motor terminal voltage and current (Simulation results)
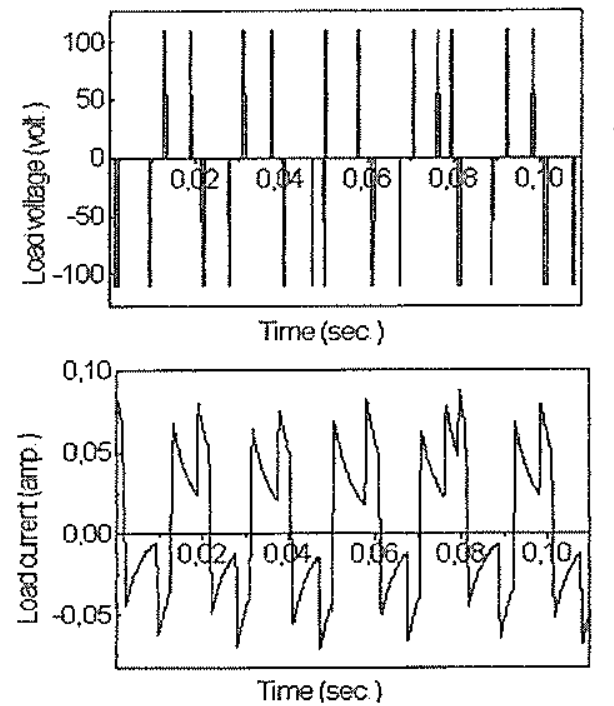

Figure 9 Steady state of motor wave forms (Simulation results) 


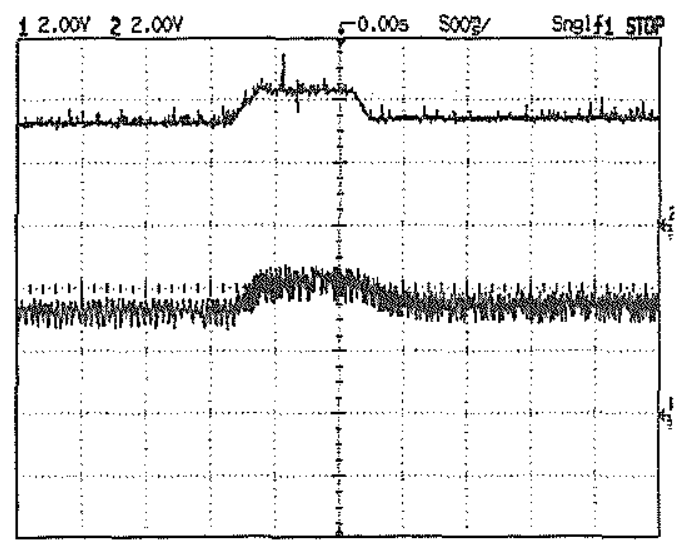

Figure 10 Experimental results (variation of reference speed)

Ch1. Reference speed

Ch2. Motor speed

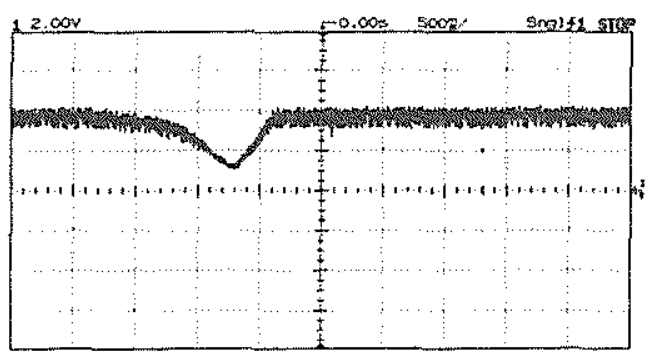

Figure 12 Experimental result of motor speed (variation of load torque)

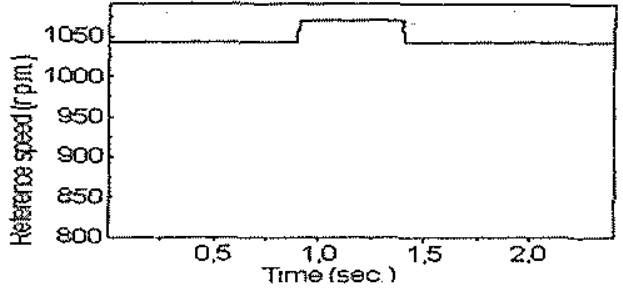

(a)

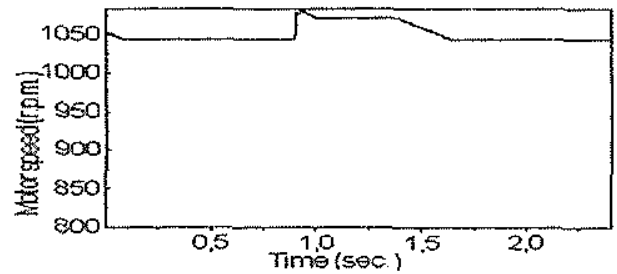

(b)

Figure 11 Simulation results (variation of reference speed)

(a) Reference speed

(b) Motor speed

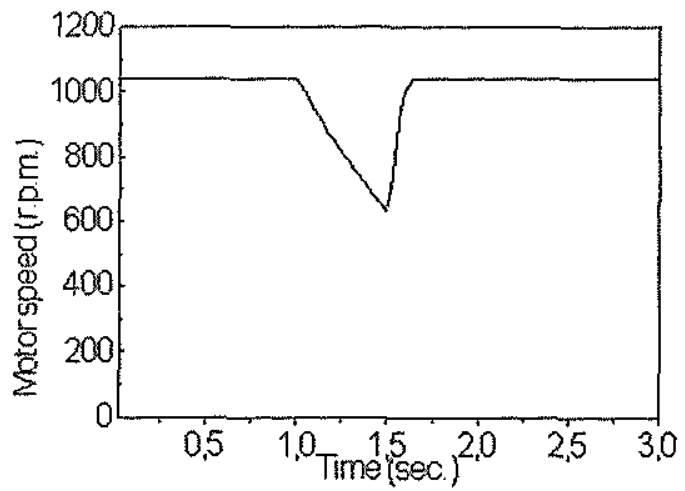

Figure 13 Simulation result of motor speed (variation of load torque) 
التحكم فى سرعة محرك حثى أحادى الوجه بإستخدام مغير

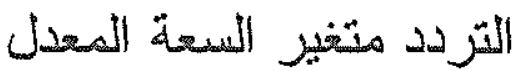

دكثور / عوض السيد اللبحع , دكتور / أشرف صلاح الدين زين الدين

قسم الهنسة الكهربية - كلية الهندسة بشبين الكوم - جامعة المنوفية

ينتاول هذا البحث طريقة جديدة للتحكم فى سرعة محرك حثنى أحسادى الوجه بإستخدام مغير التزردد متغير السعة المعلل (Modified inverter) حيث تتكون دائرة القدرة له من ثلاثة تر انزستور من اللنوع MOSFET هيث يتم

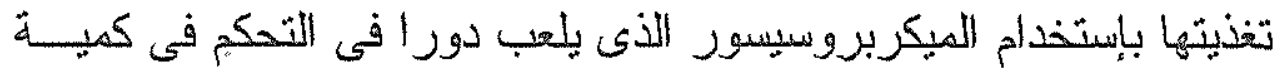

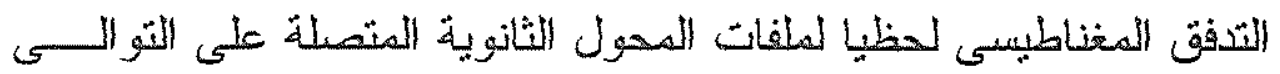

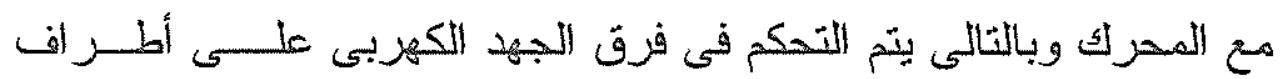

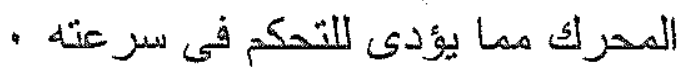

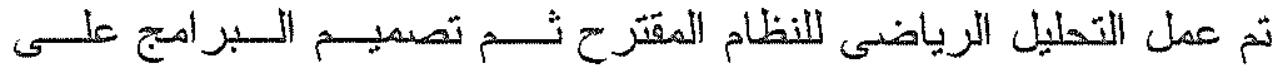

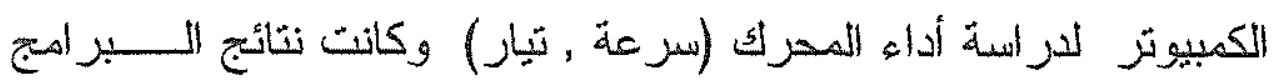
تثو افق بدرجة كبيرة ميح النتائج العملية للنظام المقترح و الأذى تـــم بنـاؤه كمليا. 